\title{
Periodontal Insert Dosage Form
}

National Cancer Institute

\section{Source}

National Cancer Institute. Periodontal Insert Dosage Form. NCI Thesaurus. Code C149751.

Solid single-dose preparation consisting of a medicated insert to be placed within the tooth socket/periodontal membrane. The biodegradable insert is a sheet which slowly releases active substance(s). 